\title{
Home-based oral healthcare strategies of elderly people with Alzheimer's disease
}

Abstract

Objective: To identify strategies used in the oral health care of elderly persons with Alzheimer's disease in the home. Method: an exploratory, descriptive study with a qualitative approach to collecting and analyzing data was performed. Data was collected through interviews with 30 caregivers and analyzed by the content analysis technique. Results: The majority of subjects were female, daughters of the elderly person, university graduates and aged 32-77 years. The strategies identified were grouped into categories according to the participation of the caregiver: does not participate in care actions or oral health assessments; reminds the elderly person about oral hygiene, demonstrates movements and Alessandra Martins Ferreira Warmling ${ }^{1,2}$ Silvia Maria Azevedo dos Santos ${ }^{2}$ Ana Lúcia Schaefer Ferreira de Mello² assists with some procedures; directly carries out actions of care. Conclusion: The strategies employed are related to the degree of dependence of the elderly person, as the caregiver acts based on the need for oral health care and the difficulties in carrying out such care.

Keywords: Alzheimer Disease. Oral Health. Home Nursing.

\footnotetext{
Universidade Federal de Santa Catarina, Programa de Pós-Graduação em Odontologia. Florianópolis, Santa Catarina, Brasil.

2 Universidade Federal de Santa Catarina, Programa de Pós-Graduação em Enfermagem. Florianópolis, Santa Catarina, Brasil. 


\section{INTRODUCTION}

Dementias are among some of the greatest challenges faced by public health. There are around 44 million people with dementia around the world, with this number expected to double by $2030 .{ }^{1}$ It is a syndrome caused by a series of progressive illnesses that affect memory, thought, behavior and the capacity to carry out everyday activities, and is one of the main causes of dependency and disability among elderly persons. It mainly affects the elderly, although it is estimated that between 2 and $10 \%$ of all cases occur before 65 years of age. ${ }^{1}$ Alzheimer's Disease (AD) is the most common type of dementia, and is responsible for approximately 50 to $75 \%$ of dementias in several countries. The symptoms generally include memory loss, communication difficulties, difficulties in performing domestic tasks, personality and mood disorders. As the disease progresses, AD sufferers experience limitations in looking after themselves and gradually come to require the help of others when performing basic activities of daily living. ${ }^{1}$

Studies have described how, due to functional and cognitive impairment, often combined with behavioral disturbances, elderly persons with AD have poor oral health conditions, ${ }^{2,3}$ and represent an at risk group for the emergence of oral disease..$^{4-6}$ Other studies have described a high prevalence of dental caries in individuals in advanced stages of $\mathrm{AD},{ }^{7}$ and found an association between the presence of dental caries in elderly persons in the initial stage of AD and a high risk of root caries. ${ }^{8-10,12}$ Issues relating to the state of oral health of elderly persons with $\mathrm{AD}$ and the way in which oral care is provided to these patients have been considered in a number of studies. ${ }^{9}$ Elderly persons that no longer have the capacity to feed themselves alone are in the majority of cases also unable to carry out oral health tasks. ${ }^{10}$ Ideally, oral health tasks are carried out by the caregiver, as it is difficult for dementia sufferers to perform these activities. ${ }^{8}$ In such cases, caregivers are the main providers of care for these patients, and therefore the planning of oral care should consider the perception of these caregivers and their knowledge of oral health and hygene. ${ }^{8}$ Furthermore, according to some authors, oral health should be reinforced by focusing on the caregivers of elderly persons with $\mathrm{AD}$, so that they can provide, in addition to daily oral health activities that maintain health and well-being, care aimed at the specific oral health care needs of elderly persons. ${ }^{9,11}$

In this context, it is important to identify the oral health strategies used by caregivers of elderly persons with AD, provided in the home, and to consider if these strategies differ according to the phase of the disease. The subject addressed in the present study is important due to the prevalence of $\mathrm{AD}$ and, above all, because of its impact on the quality of life of elderly persons. The results can add to existing literature by providing information about the daily difficulties experienced by caregivers, as well as the strategies used to overcome such difficulties. This knowledge can allow health professionals to contribute to care, valuing all those involved. Therefore, the aim of the present study was to identify the oral care strategies employed by caregivers, in the home, with elderly persons suffering from Alzheimer's Disease.

\section{METHOD}

An explorative, descriptive study was performed with a qualitative approach to the collection and analysis of data. A total of 30 caregivers of elderly persons with AD were included. The subjects were participants of a support group for caregivers and/or family members of people with AD or similar diseases. The selection of participants was intentional, or in other words, caregivers attending the meetings of the support group for caregivers and/or family members of people with Alzheimer's disease or similar diseases were invited to take part. The inclusion criteria of the participants were: be a caregiver, with or without a family relationship with the $\mathrm{AD}$ sufferer, and care for the patient in the home environment with or without financial compensation. Sampling was limited 
by the data saturation criterion, with saturation identified when the content of the discourse of the caregivers became repetitive and did not add new, relevant information related to the fulfillment of the research objectives.

Following identification of the families, initial contact with the caregiver was made, inviting him or her to participate. No refusals to participate in the interviews were recorded. Following the agreement to contribute, an interview was scheduled at the location where the meetings of the support group took place. Data collection was carried out through interviews in the period June to December 2014, and was undertaken solely by the main author of this article - a Specialist Dental Surgeon with a Master's degree in Dentistry in Public and Family Health, and a doctoral student in the Graduate Program in Dentistry, specializing in Dentistry in Public Health. The principal researcher participated in meetings of the support group for 24 months in order to learn about Alzheimer's disease and also to assist the participants with any questions they might have regarding oral health. At the meetings, the participants were informed of the presence of the researcher, who explained her reasons for being present at the meetings.

The interviews were recorded with digital equipment and were divided into two parts. First, participants responded to a structured questionnaire, which aimed to characterize the caregivers. The interview then continued with the application of a script with guiding questions on "An average day caring for elderly persons with Alzheimer's disease" and "How is oral health care of the elderly provided and what does it involve."

The data obtained from the interviews relating to the discourse of caregivers involved in oral health actions and care provided to elderly patients with AD were transcribed and analyzed based on the assumptions of Analysis of Content. ${ }^{12}$ Following the method, textual analysis was carried out in three steps: a) pre-analysis, b) exploration of and c) treatment of results, with inference and interpretation. During the pre-analysis, or data organization phase, a skim reading of the raw data was performed. The textual responses relevant to the aim of the study were then evaluated. At this stage of pre-analysis, the main themes to be used in the next stage emerged. The exploration phase of the material consisted of the coding and categorization of textual content. The data analysis process was conducted based on the identification of care strategies, which were grouped into categories according to the participation of the caregiver. ${ }^{13}$ Finally, inferences and interpretations of the processed data were performed qualitatively, analyzing the categories and their interrelations. ${ }^{12}$

To meet ethical requirements, the recommendations of National Health Council Resolution No. 466/12, which guides ethics in human research in Brazil, were followed. The project was sent to the organizers of the support group, so that they were aware of its aims and could authorize it. The project was then submitted to the Human Research Ethics Committee, which also evaluated the Free and Informed Consent Form which was individually applied to all the participants, and was approved under consubstantiated opinion $\mathbf{N}^{\mathbf{0}} 216.348$.

\section{RESULTS AND DISCUSSION}

The data shown in Table 1 below originated from the analysis of the structured questionnaires and describes the characterization of the 30 participating caregivers. 
Table 1. Characterization of caregivers. Florianópolis, Santa Catarina, Brazil, 2014.

\begin{tabular}{lc}
\multicolumn{1}{c}{ Characterization of participants } & $\mathrm{N}$ \\
\hline Profile of caregiver & 3 \\
Formal caregiver (hired to perform such function) & 27 \\
Informal caregiver (relative or close acquaintance) & \\
Relationship & 8 \\
Conjugal & 18 \\
Son/daughter & 4 \\
Friend & \\
Gender & 6 \\
Male & 24 \\
Female & \\
Educational Level & 1 \\
Incomplete Primary School & 1 \\
Complete Primary School & 1 \\
Incomplete High School & 19 \\
Complete High School & 9 \\
Incomplete Higher Education & 5 \\
Complete Higher Education & 13 \\
Performs concurrent paid activities & 11 \\
Yes & \\
No & \\
\hline
\end{tabular}

Questionnaires created by researcher of present study.

It can be seen that the majority of the respondents in the present study were informal caregivers, or in other words, were family members or friends who were asked to assume responsibility for the care that the patient required in a family context. The majority were female, and the predominant relationship was daughters, with a complete higher level education, aged between 32 and 77, who were not involved in paid employment or activities. It should be noted that while the caregivers in the present study therefore complied with the profile described in literature, where the majority of respondents are female, mainly wives or daughters, aged between 40 and 60 and who did not work, they differed in terms of schooling, as studies have found that the majority of caregivers have a low level of formal education. ${ }^{14-16}$

Analysis of the content of the interviews allowed the strategies used to be grouped into three categories, according to the participation of oral care of the caregiver, ${ }^{13}$ as can be seen in Chart 1 . 
Chart 1. Organization of strategies into categories according to the participation of the caregiver in home-based oral healthcare practices. Florianópolis, Santa Catarina, Brazil, 2014.

\begin{tabular}{|c|c|}
\hline Categories & Strategies \\
\hline "He does everything himself" & $\begin{array}{l}\text { - Does not participate in oral care } \\
\text { - Does not evaluate if oral hygiene is being performed correctly } \\
\text { - Preserves the autonomy of the elderly person }\end{array}$ \\
\hline "I help, but he does it himself" & $\begin{array}{l}\text { - Reminds elderly person to carry out oral hygiene } \\
\text { - Take the elderly person to the bathroom } \\
\text { - Demonstrates the movements that should be carried out during oral hygiene } \\
\text { through imitation in front of the mirror } \\
\text { - Helps with the performance of movements, such as putting toothpaste on the } \\
\text { brush, and taking out and putting in removable dentures } \\
\text { - Monitor the performance and quality of oral hygiene }\end{array}$ \\
\hline $\begin{array}{l}\text { "I have to do everything, he can't } \\
\text { manage anymore" }\end{array}$ & $\begin{array}{l}\text { - Brush teeth and removable dentures with brush and toothpaste } \\
\text { - Use gauze or wipes with antiseptic solution on teeth and mucous membranes }\end{array}$ \\
\hline
\end{tabular}

Interviews created by researcher of present study.

The results were presented in categories according to the participation of the caregiver in the home-based oral care practices of elderly persons with $\mathrm{AD}$, reinforcing, in accordance with literature, the role of the caregiver to monitor and assist the cared-for person, doing only what he or she cannot accomplish alone. ${ }^{17}$ It should be noted that this care is continuous and based on a single person. ${ }^{18}$ Among the main tasks of the caregiver are activities such as helping with the hygiene of the person being cared for and encouraging occupational activities, ${ }^{18}$ and in this case including oral hygiene as part of the various actions that include oral health care.

As such, when we talk about Strategies for caring for the oral health of elderly persons with $A D$, we will present and discuss the findings in each category, starting with "He does everything alone".

The 11 caregivers in this category said they did not participate in the oral health care of elderly persons with $\mathrm{AD}$. In these cases, it is the elderly person, alone, who carries out his or her oral hygiene. Of the 11 caregivers, seven said their oral health activities involved the cleaning of removable dentures with the use of a brush and toothpaste. The other four also reported also brushing teeth with a brush and toothpaste. Oral hygiene takes place after meals and before bedtime, according to six caregivers; once a day, generally in the morning, according to four caregivers; and one caregiver reported that the elderly person brushed his or her teeth several times a day. Flossing was reported by only one caregiver, with the elderly person using it only in case of discomfort resulting in something stuck to the teeth. The dialogue below expresses the views of a large number of the caregivers:

[...] Oral bygiene is carried out after lunch, she brushes
her teeth like she always did, she can still do this part
alone ... at least three times a day, in the morning, in
the afternoon after lunch and at night when taking a
shower before sleeping. She uses a brush and toothpaste,
as she has done all her life, but nothing has changed and
she hasn't forgotten ... but she only flosses when she has
something stuck in her teeth [...] (PW).

It is notable that in this category the caregivers did not participate in oral hygiene at any time, either by performing care, by helping or reminding or even by checking if the hygiene has been performed correctly. Such situations often develop as a means of avoiding situations of conflict with the elderly and also in order to maintain their privacy, independence and autonomy. 
In contrast, five caregivers said no assistance was provided at the time of performing oral hygiene, as the elderly person did not allow or accept help, as can be seen from the following extract:

[...] She finishes lunch and goes to the bathroom to brush her teeth, except she is no longer able to do it, nor able to tell if she has done it right and so on, I don't think she is able to perform the movements required to brush her teeth, and she can't tell if she's doing it right. But she goes alone, she goes to the bathroom and knows what she has to do, she won't let me go with her, she closes herself in the bathroom. And I let her, to avoid an argument [...] (SM).

According to the reports, in these cases, in which the elderly person performs oral hygiene alone, he or she usually carries out such hygiene in the same manner as before the diagnosis of disease and in accordance with the guidelines of his or her Dental Surgeon.

[...] She still does it the way she did it her whole life, we learnt together, during visits to the dentist, and from the instructions that the dentist gave her about brushing her teeth and cleaning her mouth. I don't do it, I let her do it the way she has always done it, the way the dentist taught her, she's looked after the teeth of her five children, she's cared for them well since they were kids. I think that that's the best way, I think she does it the best way she can, every day [...] (RM).

The analysis of the interviews showed limited awareness among caregivers of the need for specific oral health care aimed at elderly persons with AD. Caregivers must be aware that there is an ongoing need for oral care, even for elderly persons in the early stages of $\mathrm{AD}$.

Oral health studies have identified issues related to the oral health status of elderly patients with $\mathrm{AD}$ and the way oral health care is administered to these patients. ${ }^{8-11}$ They indicate issues such as the loss of capacity of elderly persons with AD to eat alone, relating this loss to the fact that they also fail to perform their dental hygiene ${ }^{10}$. Caregivers should be attentive to this issue, as the fact that the elderly person has lost the ability to feed himself or herself can be an indication of the loss of other capabilities, such as the ability to perform oral care. The caregiver is therefore required to perform this function.

Given the above, caregivers need to use other strategies to encourage the performance of suitable oral hygiene. One such approach found in this study is assistance, as described by the next category.

"I help, but he does it". In this category, seven caregivers reported that they participated in the oral care of elderly with AD. During such participation, the caregivers make use of strategies such as: reminding the elderly person to carry out oral hygiene, taking the elderly person to the bathroom, and demonstrating the movements that must be carried out to perform oral hygiene. In these cases, the elderly person carries out their oral hygiene and the caregiver accompanies them by monitoring the quality of the actions.

[...] We don't do it for her, but we always have to remind her, and ask her, let's clean our teeth, it's time to clean your teeth, so we ask her to do it and then monitor the brushing. She won't let us do it [...] (RE).

The seven caregivers described how participating in oral care is based on the following strategies: reminding the elderly person to perform oral hygiene tasks; helping the elderly person to perform movements such as putting toothpaste on the toothbrush, taking out and putting in removable dentures; and showing the elderly person, by demonstration in front of the mirror, the steps to be carried out when performing oral hygiene.

[...] She brushes by herself, we just do the movements sometimes because she forgets. She brushes her teeth too, and puts the brush in every part of her mouth. Sometimes she spits and sometimes she doesn't. I think she swallows. She puts water in her mouth with her hand and doesn't know what to do. So I make the movement that she has to do in the mirror and she imitates me [...] (LF).

This category includes caregivers who participate in oral care, not by carrying it out, but by helping, reminding and evaluating whether it is being done properly. This is because although the 
elderly persons do not remember that they need to perform oral hygiene, when accompanied and guided they are able to perform such activities.

According to reports, in cases where the caregiver assists the elderly person to perform oral hygiene, he or she usually does so in the same way as before the diagnosis of disease and in accordance with the directions of his or her dental surgeon, and also by trial and error, due to not having received specific guidelines for the oral care of elderly persons with $\mathrm{AD}$.

[...] We try... but she doesn't have teeth and she hasn't used dentures for a long time, so she eats baby food. I've never had any instructions, no one explained anything about brushing her teeth after she got sick [...] (AM).

Studies show that the family caregiver of a dependent elderly person is overburdened from a physical and mental point of view by the accumulation of functions and types of tasks he or she assumes, which generally go beyond the simple monitoring of activities of daily living. ${ }^{18}$

The task of caring is complex, permeated by diverse and contradictory feelings and often given to individuals who are not prepared for such actions. Typically, this responsibility is transferred as an extra burden for the family, who, within their daily lives, are obliged to assume another function in addition to those they already perform. ${ }^{19}$ According to literature, these caregivers may present situations of crises, due to carrying out sometimes tedious, repetitive and stressful functions. ${ }^{20}$ The primary caregiver has the greatest overburden as he or she assumes greater or full responsibility for care, devoting most of his or her time to caring for the sick family member. ${ }^{21}$ This situation can cause physical, psychological, emotional, social and financial problems, which ultimately affect both the well-being of the caregiver and the elderly person that he or she cares for. As a solution, literature points to the construction of a support network involving different family members, friends, neighbors and health services as a healthy and desirable strategy for assisting with home care. ${ }^{22}$

Due to the complexity of the tasks performed, caregivers end up developing care skills, which facilitate their daily activities and are aimed at preventing accidents and complications to the health of the elderly, promote their physical and mental well-being, organize the physical space around them, and develop and utilize care and feeding technologies. ${ }^{23}$

Another noteworthy finding in the present study was that when caregivers discuss using strategies such as reminding elderly persons to carry out oral hygiene, taking them to the bathroom and demonstrating movements by imitation, they describe these actions as oral care, as though oral health is exclusively related to oral hygiene. Oral health care is a day-to-day construction that goes beyond the present space and time and requires an integral vision of human beings and their relations with other beings, society and the environment. Oral healthcare guides practices that have a direct effect on improving oral health, and are not restricted to habits and behaviors. Oral health care should also be an inseparable and articulated component of any comprehensive care system for the health of the elderly. ${ }^{24}$

It is difficult for elderly persons with AD to perform proper oral hygiene. Ideally, such procedures should be performed by the caregiver. Where this happens the main provider of oral care should therefore be responsible for planning these procedures, inserted within a broader oral care plan, which should include periodic assessments of oral health conditions in the home, as well as verification of the need for dental appointments and facilitating access to the dentist. ${ }^{10}$

At the same time, with the advancement of $\mathrm{AD}$, the caregiver becomes the main provider of oral care, which is often a causer of worry and stress, as it is not an easy task to accomplish. The category below describes part of this reality and the efforts of caregivers to try to maintain suitable oral hygiene in elderly persons with dementia.

"I have to do everything, he can't do it anymore". In this category 12 caregivers said that they performed oral care, as the elderly person could no longer carry out his or her oral hygiene alone. Among these 12 caregivers, eight said that the oral care they performed was brushing of teeth and removable 
dentures with a brush and toothpaste. And the other four said that oral hygiene was carried out with wipes or gauze and some type of antiseptic solution that was spread on the teeth and gums, usually once or twice a day.

[...] He can't carry out his oral hygiene tasks. He's like a baby. He doesn't like to floss, but sometimes I do it. He uses mouthwash, but sometimes he swallows it, or spits it on the floor or over the tap, I say, "bere, here in the sink," but he misses a lot, be can't hit it, I'm always with bim. As he sometimes swallows it I just use a little liquid. And when I notice that he is swallowing a lot I give him water [...] (MD).

In this category, the caregivers reported difficulties in performing oral hygiene, because of the non-cooperation of the elderly, who bite, clamp their teeth closed or simply refuse to allow oral hygiene to take place.

[... It's very hard to brush his teeth these days, sometimes we roll ganze around our finger to spread antiseptic solution. One of the caregivers who helps me doesn't do oral hygiene tasks because be bit her twice, while the other carries out oral hygiene with gauze wrapped around the toothbrush [...] $(\mathrm{Z} A)$.

The issue of caregivers performing oral care, without the participation of the elderly, appears in this category. This is because the elderly persons are no longer able to carry out their oral hygiene and cannot remember what needs to be done nor how it should be done.

According to the reports, in cases where the caregiver performs oral hygiene, he or she often does so by trial and error, experimenting with what works as specific guidelines for the oral care of the elderly persons with AD have not been provided, or based on the guidelines of the dental surgeon, or instructions received in hospitals, if the elderly person has been hospitalized at some point.

As can be seen, several care strategies may be used by caregivers, because their work goes beyond the desire to take care of a family member, given the complexity of care required. It involves knowledge, the development of skills, initiatives for the prevention and treatment of disease and the promotion and recovery of elderly health. ${ }^{22}$ Factors related to poor oral health, such as dental caries, periodontal diseases, along with xerostomia inducing drugs, reduced fine motor skills and cognitive decline, can lead to an increase in morbidity and mortality and impact the quality of life of the elderly with AD. ${ }^{25}$

While the data collected from the interviews was focused on the oral care strategies performed by a group of caregivers, the methodology used also allowed information to be obtained relating to the perception of the caregivers of the care they provide. This information is important for the healthcare of AD patients, including the oral health of those in this situation.

Providing care at home involves a number of activities that must be planned together with health professionals. The role of the dentist is important, as his or her partnership with the caregiver can enable the systematization of oral care to be carried out in this context, prioritizing actions related to health promotion, the prevention of oral diseases and the maintenance of oral health.

It is also important to emphasize the need for dentists who are more prepared to communicate with and treat elderly patients with $\mathrm{AD}$ and their caregivers in both the private and public services, and who can contribute to the care of dependent elderly persons in the home. Care and instruction for elderly persons and caregivers in the home environment is also important.

\section{CONCLUSION}

A limitation of this study is the fact that data was obtained through a purposive sample, which prevents the wider use of its results. Despite this, the findings provide useful benefits in the practical field, as it identified the strategies used in the home-based oral health care of elderly people with Alzheimer's Disease. The strategies identified were grouped into categories based on the participation of the caregiver, which is related to the degree of dependence of the elderly person with AD. 
The results have practical implications, especially for home dentistry, highlighting the need for specific protocols related to oral health care performed in this context. These protocols should be developed not only to facilitate the day to day life of caregivers, helping them to overcome the daily obstacles of spending time with an elderly person with $\mathrm{AD}$, but also to carry out actions of scientifically based care that allows good oral health conditions to be maintained for such individuals.

The oral health care strategies identified can serve as a guide and assist in the consolidation of the professional practice of home care within the Primary Health Care system. In this way, health professionals will become closer to the population and, therefore, can potentially contribute more directly to care through consultations at health

\section{REFERENCES}

1. Prince M, Albanese E, Guerchet M, Prina M. World Alzheimer Report 2014. Dementia and risk reduction: an analysis of protective and modifiable factors [Internet]. London: Alzheimer's Disease International; 2014 [acesso em 04 /10/2014]. Disponível em: http://www.alz.co.uk/research/ WorldAlzheimerReport2014.pdf

2. Balthazar MLF, Damasceno BP, Cendes F. Demências. RBM Rev Bras Med 2011;68(6):183-93.

3. Ribeiro GR, Costa JLR, Ambrosano GMB, Garcia RCMR. Oral health of the elderly with Alzheimer's disease. Oral Surg Oral Med Oral Pathol Oral Radiol 2012;114(3):338-43.

4. Mancini M, Grappasonni I, Scuri S, Amenta F. Oral health in Alzheimer's disease: a review. Curr Alzheimer Res 2010;7(4):368-73.

5. Martande SS, Pradeep AR, Singh SP, Kumari M, Suke DK, Raju AP, et al. Periodontal health condition in patients with Alzheimer's disease. Oral health in Alzheimer's disease: a review. Am J Alzheimers Dis Other Demen 2014;29(6):498-502.

6. Ferreira RC, Vargas AMD, Fernandes NCN, Souza JGS, Sá MAB, Oliveira LFB, et al. O idoso com comprometimento cognitivo apresenta pior condição de saúde bucal? Ciênc Saúde Coletiva 2014;19(8):3417-28. centers and in the home and by guiding caregivers in groups and/or individually. In this way, they can get to know the reality of each family and plan together the most appropriate strategies for the specific care of each elderly individual with AD.

\section{ACKNOWLEDGEMENTS}

We would like to thank the Coordenação de Aperfeiçoamento de Pessoal de Nível Superior (Coordination for the Improvement of Higher Education Personnel) (CAPES) for financial support through a doctoral scholarship; and the Associação Brasileira de Alzheimer Regional Santa Catarina (Santa Catarina Office of the Brazilian Alzheimer's Association) (ABRAz - SC) in the city of Florianópolis, state of Santa Catarina (Brazil).

7. Ellefsen BS, Morse DE, Waldemar G, HolmPedersen P. Indicators for root caries in danish persons with recently diagnosed Alzheimer's disease. Gerodontology 2012;29(3):194-203.

8. Luo J, Wu B, Zhao Q, Guo Q, Meng H, Yu L, et al. Association between tooth loss and cognitive function among 3063 chinese older adults: a community-based study. PLoS ONE 2015;10(3):1-11.

9. Arai K, Sumi Y, Uematsu H, Miura H. Association between dental health behaviours, mental/physical function and self-feeding ability among the elderly: a cross-sectional survey. Gerodontology 2003;20(2):78-83.

10. Sumi Y, Ozawa N, Michiwaki Y, Washimi Y, Toba K. Oral conditions and oral management approaches in mild dementia patients. Nihon Ronen Igakkai Zasshi 2012;49(1):90-8.

11. Chen X, Clark JJ, Chen H, Naorungroj S. Cognitive impairment, oral self-care function and dental caries severity in community-dwelling older adults. Gerodontology 2015;32(1):53-61.

12. Bardin L. Análise de conteúdo. São Paulo: Edições 70; 2011.

13. Brasil. Ministério da Saúde, Secretaria de Atenção à Saúde, Secretaria de Gestão do Trabalho e da Educação na Saúde. Guia prático do cuidador. Brasília, DF: Ministério da Saúde; 2008. 
14. Vieira CPB, Fialho AVM, Freitas CHA, Jorge MSB. Práticas do cuidador informal do idoso no domicílio. Rev Bras Enferm 2011;64(3):570-9.

15. Bauab JP, Emmel MLG. Mudanças no cotidiano de cuidadores de idosos em processo demencial. Rev Bras Geriatr Gerontol 2014;17(2):339-52.

16. Gonçalves LHT, Nassar SM, Daussy MFS, Santos SMA, Alvarez AM. O convívio familiar do idoso na quarta idade e seu cuidador. Ciênc Cuid Saúde 2011;10(4):746-54.

17. Brasil. Ministério da Saúde, Secretaria de Atenção à Saúde, Secretaria de Gestão do Trabalho e da Educação na Saúde. Guia prático do cuidador. $2^{a}$ ed. Brasília, DF: Ministério da Saúde; 2009.

18. Vieira L, Nobre JRS, Bastos CCBC, Tavares KO. Cuidar de um familiar idoso dependente no domicílio: reflexões para os profissionais da saúde. Rev Bras Geriatr Gerontol 2012;15(2):255-264.

19. Brasil. Ministério da Saúde, Secretaria de Atenção à Saúde, Departamento de Atenção Básica. Caderno de Atenção Domiciliar. Vol. 1. Brasília, DF: Ministério da Saúde; 2012.
20. Almeida LGRS, Jardim MG, Franco ECD. O cuidar do idoso com Alzheimer: sentimentos e experiências vivenciados por seus cuidadores. Rev Enferm UFSM 2014;4(2):303-12.

21. Borghi AC, Castro VC, Marcon SS, Carreira L. Sobrecarga de familiares cuidadores de idosos com doença de Alzheimer: um estudo comparativo. Rev Latinoam Enferm 2013;4(7):1-7.

22. Brondani CM, Beuter M, Alvim NAT, Szareski C, Rocha LS. Cuidadores e estratégias no cuidado ao doente na internação domiciliar. Texto \& Contexto Enferm 2010;19(3):504-10.

23. Floriano LA, Azevedo RCS, Reiners AAO, Sudré MRS. Cuidado realizado pelo cuidador familiar ao idoso dependente, em domicílio, no contexto da estratégia de Saúde da Família. Texto \& Contexto Enferm 2012;21(3):543-8.

24. Mello ALSF, Erdmann AL. Revelando contradições e incorporando melhores práticas no cuidado à saúde bucal de idosos. Physis (Rio J.) 2007;17(1):139-56.

25. Foltyn P. Ageing, dementia and oral health. Aust Dent J 2015;60(1):86-94. 